with prednisone with good clinical response but relapse of arthritis at discontinuation followed by the development of a sterile muscle abscess. An anti-TNF drug was started in both patients with complete clinical response. Patient 5 reported severe acne and psoriasis, and recurrent episodes of sterile arthritis. She presented a persistent elevation of acute phase reactants with severe anemia and leukopenia not resolving after splenectomy. His son (pts 6) presented with recurrent episodes of sterile arthritis, hepato-splenomegaly, anemia and neutropenia. Zinc and calprotectin serum levels resulted respectively $728 \mathrm{micromol} / \mathrm{l}$ and $2600 \mathrm{microg} /$ $\mathrm{ml}$. IL-1 inhibition determined a complete normalization of inflammatory parameters with no effects on anemia and neutropenia. In patient 6 zinchemia decreased to almost normal value after 4 months of therapy. Patient 7 presented at the age of 4 years a sterile lymphnode abscess. She also presented with splenomegaly and neutropenia with persistent elevation of acute phase reactants. Anakinra was proposed but not administered for poor compliance

Conclusion: The clinical picture of patients carrying PSTPIP1 mutation may be heterogeneous. In our cohort TNF-inhibitors were successfully used in PAPA patients preventing new arthritis episodes and resolving cutaneous manifestation where present. In 2 patients the clinical picture was mild not requiring continuous treatment. One PAMI patient had a good response to IL-1 inhibition, which however, had no effect on hematological manifestations

\begin{tabular}{|c|c|c|c|c|}
\hline Pts & Mutation & Clinical features & Laboratory features & Therapy \\
\hline 1 & A230T & $\begin{array}{l}\text { Recurrent fever, acne, cutaneous absesses, } \\
\text { arthritis }\end{array}$ & $\uparrow \mathrm{CRP}, \mathrm{ESR}, \mathrm{SAA}$ & Anti-TNF \\
\hline 2 & A230T & Acne, arthritis & $\uparrow$ CRP, ESR, SAA & Anti-TNF \\
\hline 3 & R405C & Recurrent fever & $\uparrow$ CRP, ESR, SAA, zincaemia & 1 \\
\hline 4 & $\mathrm{D} 266 \mathrm{~N}$ & Recurrent fever & $\uparrow$ CRP, ESR, SAA, zincaemia & 1 \\
\hline 5 & $\mathrm{E} 250 \mathrm{~K}$ & $\begin{array}{l}\text { Acne, psoriasis, arthritis, } \\
\text { hepatosplenomegaly }\end{array}$ & $\begin{array}{l}\text { } \text { CRP, ESR, SAA, zincaemia } \\
\text { calprotectinemia }\end{array}$ & 1 \\
\hline 6 & E250K & arthritis, hepatosplenomegaly & $\begin{array}{l}\uparrow \text { CRP, ESR, SAA, zincaemia } \\
\text { calprotectinemia }\end{array}$ & Anti IL-1 \\
\hline 7 & E250K & Limphnode absess, hepatosplenomegaly & $\uparrow C R P$, ESR, SAA & 1 \\
\hline
\end{tabular}

Disclosure of Interests: : Silvia Federici: None declared, Camilla Celani: None declared, Virginia Messia: None declared, Giulia Marucci: None declared, christoph kessel: None declared, Fabrizio De Benedetti Grant/ research support from: Abbvie, SOBI, Novimmune, Roche, Novartis, Sanofi, Pfizer, Antonella Insalaco: None declared DOI: 10.1136/annrheumdis-2019-eular.6176

\section{SAT0498 THE IMPACT OF OVERWEIGHT ON THE OUTCOME OF JUVENILE IDIOPATHIC ARTHRITIS}

Juliane Riess ${ }^{1}$, Ivan Foeldvari ${ }^{2} .{ }^{1}$ Semmelweis University, Asklepios Campus Hamburg, Hamburg, Germany, ${ }^{2}$ Hamburger Zentrum für Kinder- und Jugendrheumatologie, Hamburg, Germany

Background: Overweight and obesity are considered to have a negative impact on Rheumatoid Arthritis in adults and there is less information regarding the correlation in juvenile idiopathic arthritis(JIA).

Objectives: To assess the effect of overweight on the activity of JIA as well as the stability and ability to achieve a remission using the cJADAS-10 score.

Methods: This is a longitudinal retrospective study design. We collected data of 164 patients suffering from JIA from three consecutive visits. Treatment was conducted between 2012 and 2015 at our centre in accordance to current guidelines. Remission was defined by cJADAS10 score $\leq 0,5$ in Oligoarthritis and $\leq 0,7$ in Polyarthritis. Patients were categorized by weight-for-age percentiles as heavily underweight (less than $3^{\text {rd }}$ percentile) underweight ( $4^{\text {th }}$ up to $10^{\text {th }}$ percentile) healthy $\left(11^{\text {th }}\right.$ up to $90^{\text {th }}$ percentile) overweight $\left(91^{\text {th }}\right.$ up to $96^{\text {th }}$ percentile) and obese ( $97^{\text {th }}$ up to $100^{\text {th }}$ percentile). We compared the cJADAS10 of normal-weighted children with the CJADAS10 of the overweight and the obese patients, respectively.

Results: Of all patients, 13 were "underweight" (7,9\%), 109 were defined as "normal weight" $(66,5 \%)$ and 42 patients were categorized as "overweight" (25,6\%) of which 16 children (9,8\%) were "obese". 95 (57.9\%) reached a remission during follow-up visits. Overweight was associated with higher disease activity compared to healthy weight children at the first visit (mean 9,5 vs. 8,5) and a wider range of the cJADAS10 score $(0-22$ vs.0-20,5). Results from the 3 -months-follow-up revealed an overall good response to the prescribed medication. At 6-months-follow-up, overweight children couldn't stabilize the improvement since cJADAS10 range rises while it stays stable in healthy weight children. At the same time, while interpreting the disease activity of "overweight" and "obese" children separately, obese children show significantly less disease activity than overweight children, especially at the 3- and 6-months-follow-ups.

Conclusion: Overweight seems to have a negative influence on the disease activity and remission of JIA patients but it is most likely not the only influencing factor since obese patients show a better result regarding the cJADAS10 score than overweight patients. In the future, factors like socioeconomic status, BMI of the parents or physical activity level of the patient should be included in the evaluation. Also, the 7 subtypes of JIA should be analyzed individually since they show heterogeneous etiology, phenotype and prognosis.

Disclosure of Interests: Juliane Riess: None declared, Ivan Foeldvari Consultant for: Chugai

NovartisDOI: 10.1136/annrheumdis-2019-eular.3017

\section{SAT0499 ORAL MICROBIOME IN CHILDREN WITH JUVENILE IDIOPATHIC ARTHRITISIN RELATION TO DISEASE STATUS, TEMPOROMANDIBULAR JOINT ARTHRITIS AND MEDICATION: A NORWEGIAN 2-YEAR PROSPECTIVE STUDY}

Paula Frid $^{1}$, Josefine Halbig ${ }^{2}$, Divyashri Baraniya ${ }^{3}$, Veronika Rypdal ${ }^{4}$, Nils Thomas Songstad $^{5}$, Annika Rosen ${ }^{6}$, Johanna Rykke Berstad ${ }^{7}$, Berit Flato ${ }^{8}$, Tsute Chen ${ }^{9}$, Nezar Noor Al-Hebshi ${ }^{10}$, Ellen Nordal ${ }^{5}$, Mohammed Al-Haroni ${ }^{11}$, Norwegian multicenter NorJIA cohort study. ${ }^{1}$ UiT The Arctic University of Norway, Tromso, Norway, Department of Otorhinolaryngology, Division of Oral and Maxillofacial Surgery, University Hospital North Norway and Public Dental Service Competence Centre of North Norway and Department of Clinical Medicine, Tromso, Norway; ${ }^{2}$ UiT The Arctic University of Norway, Tromso, Norway, Public Dental Service Competence Centre of North Norway and Department of Clinical Dentistry, Tromsø, Norway, ${ }^{3}$ Temple University, Philadelphia, PA, USA, Oral Microbiome Research Laboratory, Maurice H. Kornberg School of Dentistry, Philadelphia, United States of America; ${ }^{4}$ UiT The Arctic University of Norway, Tromso, Norway, Department of Clinical Medicine and Department of Pediatrics, Tromso, Norway; ${ }^{5}$ UiT The Arctic University of Norway, Tromso, Norway, Department of Clinical Medicine and Department of Pediatrics, Tromso, Norway, Tromso, Norway; ${ }^{6}$ University of Bergen, Department of Clinical Dentistry and Haukeland University Hospital, Bergen, Norway, Bergen, Norway, ${ }^{7}$ University of Oslo, Department of ENT and Oral and Maxillofacial Surgery, Oslo University Hospital, Oslo, Norway, Oslo, Norway, ${ }^{8}$ University of Oslo, Department of Rheumatology, Oslo University Hospital, Oslo, Norway, Oslo, Norway; ${ }^{9}$ Forsyth Institute, Cambridge, USA, Department of Microbiology, Cambridge, United States of America; ${ }^{10}$ Temple University, Philadelphia, PA, USA, Oral Microbiome Research Laboratory, Maurice H. Kornberg School of Dentistry, Philadelphia, United States of America; ${ }^{11}$ UiT The Arctic University of Norway, Tromso, Norway, Department of Clinical Dentistry, Tromso, Norway

Background: Juvenile idiopathic arthritis (JIA) is the most common chronic rheumatic disease in children, with an annual incidence of 1-2 per 1000 children. The temporomandibular joint (TMJ) is involved in 40 $70 \%$. The human microbiome might be a potential contributing factor to the development of JIA.

Objectives: To describe the oral salivary microbiome in children with JIA and relate this to disease activity, TMJ arthritis, and systemic medications.

Methods: 93 children; JIA $(n=59)$, Healthy $(n=34)$ were recruited. Demo graphics, disease activity, presence of TMJ-arthritis and type of medication was collected in this Norwegian prospective study (www.norjia.com) 116 saliva samples were analyzed using Next Generation Sequencing, V1-V3 region of the 16S rRNA gene, coupled with BLASTn-based, species-level taxonomy assignment algorithm. Downstream bioinformatics analysis was performed with QIIME and LEfSe.

Results: Mean age for healthy group ( $\mathrm{n}=34 ; 27$ females) is $12.3 \pm 3.0$ years while for the JIA group ( $n=59 ; 43$ females) the mean age is 12.6 \pm 2.7 years. A total of 541 bacterial species belonging to 111 genus and 10 phyla were identified, with Prevotella, Streptococcus, Actinomyces, Rothia Haemophilus and Veillonella accounting for the bulk of the average microbiome. There were no significant difference between JIA and healthy subjects in species richness and alpha diversity. However, differential abundance analysis revealed genera TM7-G1, Solobacterium and Mogibacterium to be associated with JIA, while Haemophilus and Lactococcus to be overabundant in healthy subjects.

Conclusion: It seems that taxa associated with chronic inflammation were found to be enriched in the saliva of JIA patients. 